\title{
A paisagem e os alunos de graduação do Departamento de Geografia da Faculdade de Filosofia, Letras e Ciências Humanas (FFLCH), da Universidade de São Paulo (USP)
}

\author{
Yuri Tavares Rocha ${ }^{1}$
}

\begin{abstract}
Resumo: Na Geografia, o estudo dos arranjos espaciais pode ser feito por diversas categorias ou unidades de análise geográfica, como espaço, região, território, lugar e paisagem. A adoção dessas categorias gerou diferentes linhas do pensamento geográfico. Tais fatos proporcionaram uma riqueza teórico-metodológica muito importante para a ciência geográfica e que se refletiu em suas linhas de pensamento, inclusive naquela que adotou a paisagem como unidade de análise geográfica. Objetivando compreender o entendimento sobre paisagem que os alunos do Bacharelado em Geografia do Departamento de Geografia/FFLCH/USP possuem antes de cursar a disciplina optativa Teoria Geográfica da Paisagem, realizou-se aplicação de questionários nas turmas de 2006 a 2011 da referida disciplina sob minha responsabilidade. A análise dos resultados permitiu comparar: a) a estrutura curricular de cursos de bacharelado em Geografia das universidades estaduais paulistas quanto à categoria de análise geográfica paisagem; b) verificar a existência de disciplinas que tratam da paisagem antes dos alunos cursarem a disciplina específica no Bacharelado em Geografia da USP; c) conhecer as principais definições sobre paisagem elaboradas pelos alunos; d) conhecer os autores já conhecidos por eles previamente $e$ as fontes desse conhecimento; e) e, propor mudanças que valorizem a paisagem como categoria de análise geográfica na formação dos geógrafos pelo Departamento de Geografia/FFLCH/USP.
\end{abstract}

Palavras-chave: Geografia; paisagem; graduação; estrutura curricular.

\section{Landscape and undergraduate students of the Department of Geography, Faculty of Philosophy, Letters and Human Sciences, University of São Paulo}

Abstract: In geography, the study of spatial arrangements can be made by various categories or geographic units of analysis, such as: space, region, territory, place, and landscape. The adoption of these categories generated different lines of geographical thought, providing theoretical and methodological approaches that were very important for geographical science and its thought lines, including the approach that adopts the landscape as a geographic unit of analysis. Aiming to understand the knowledge about landscape that students of the Bachelor of Geography from the Department of Geography/FFLCH/USP have before attending elective discipline Landscape Geographic Theory, they answered questionnaires from 2006 to 2011. Analysis of the results allowed the comparison of: a) the curricular structure of the undergraduate major in Geography among the Sao Paulo State Universities; b) verify among the universities the existence of disciplines about landscape; $c$ ) investigate the main definition about landscape elaborated by the students; d) investigate the authors and literature's sources previously known by students; e) and finally suggest

\footnotetext{
${ }^{1}$ Engenheiro Agrônomo, Mestre e Doutor em Geografia, coordenador do Working Group Urban Landscapes in Tropical Cities (International Society for Horticultural Science) e líder dos grupos de pesquisa "Paisagens naturais e urbanas" e "Biogeografia" (Diretório dos Grupos de Pesquisa - CNPq). Professor Doutor do Departamento de Geografia/Faculdade de Filosofia, Letras e Ciências Humanas/Universidade de São Paulo, Av. Prof. Lineu Prestes, 338 - Cidade Universitária - 05508-000, São Paulo (SP) - E-mail: yuritr@usp.br
} 
changes that can increase the value of landscape as a category of analysis in the education of the students majoring in Geography at the Department of Geography, University of São Paulo.

Key-words: Geography; landscape; undergraduate; curriculum.

\section{INTRODUÇÃO}

O termo paisagem apresenta grande complexidade porque é adotado por diversas áreas de expressão e conhecimento da humanidade, desde as artes (iconografia, literatura, etc.) até as diferentes áreas da ciência (Geografia, Arquitetura, Antropologia, Psicologia, etc.), como também está presente na elaboração de projetos de ordenamento territorial e planejamento ambiental, carregando múltiplos níveis de significados. Por essa razão, a paisagem é um termo polissêmico nos aspectos etimológicos e científicos e uma das categorias espaciais utilizadas, principalmente, pela Geografia, pela Ecologia e pela Arquitetura.

Nos aspectos da etimologia, a citação mais antiga da palavra paisagem encontrada na literatura mundial está no Livro dos Salmos, originada da palavra hebraica noff, provavelmente relacionada etimologicamente a yale (belo); foi usada na referência a uma bela visão geral de Jerusalém, com os templos e palácios do rei Salomão (reinou entre 1009 a 922 a.C.), principalmente o Templo de Jerusalém, também conhecido como o Templo de Salomão, no Monte Moriá (NAVEH; LIEBERMAN, 1994).

A palavra paisagem nas línguas latinas (paysage - francês, paesaggio - italiano, paisaje espanhol) teria surgido somente no final da Idade Média e início da Renascença, assim como as palavras relacionadas a ela nas línguas anglo-saxônicas: landschap - holandês, Landschaft - alemão, landscape - inglês. Em português, a palavra paisagem vem do termo francês paysage, que por sua vez se refere ao vocábulo pago, ainda hoje utilizado no estado do Rio Grande do Sul; originado do latim pagus, que designava "os marcos colocados no solo para delimitar um território e, ao sufixo 'agem' relacionado à ação do homem sobre o território demarcado" (CAVALHEIRO, 2004, p. 449).

Nas línguas orientais, paisagem está relacionada aos elementos da natureza (vales, montanhas, água, etc.) e, nas latinas ou neolatinas, aparece relacionada ao território; no ocidente, a palavra paisagem está ligada, geralmente, à presença humana no contexto 
espacial, enquanto nas línguas orientais, está diretamente relacionada à natureza (PRESOTTO; ROCHA, 2010).

A paisagem, quando considerada pelos métodos científicos das distintas áreas da ciência, apresenta conceitos diversos e complexos. A Geografia é uma das ciências que consideram a espacialidade como fundamental porque estuda o espaço terrestre transformado pela ação antrópica e todos os fenômenos desse processo; pode ser entendida como o "(...) único setor do conhecimento que se interessa pela investigação da natureza - a ecosfera - e dos complexos mecanismos que explicam o arcabouço social - a antroposfera (CONTI, 1998, p.147). O mesmo autor concluiu que a Geografia é, “(...) essencialmente, a ciência que estuda os arranjos espaciais (desde a macroescala até a escala local) resultantes dessa permanente ação recíproca entre o homem e a natureza e nisso reside a essência de sua identidade".

Dentro da Geografia, o estudo desses arranjos espaciais pode ser feito por diversas categorias ou unidades de análise geográfica, tais como espaço, região, território, lugar e paisagem (Figura 1). A adoção dessas categorias gerou diferentes linhas do pensamento geográfico que existem e existiram na Geografia desde o século XVIII (Figura 2).

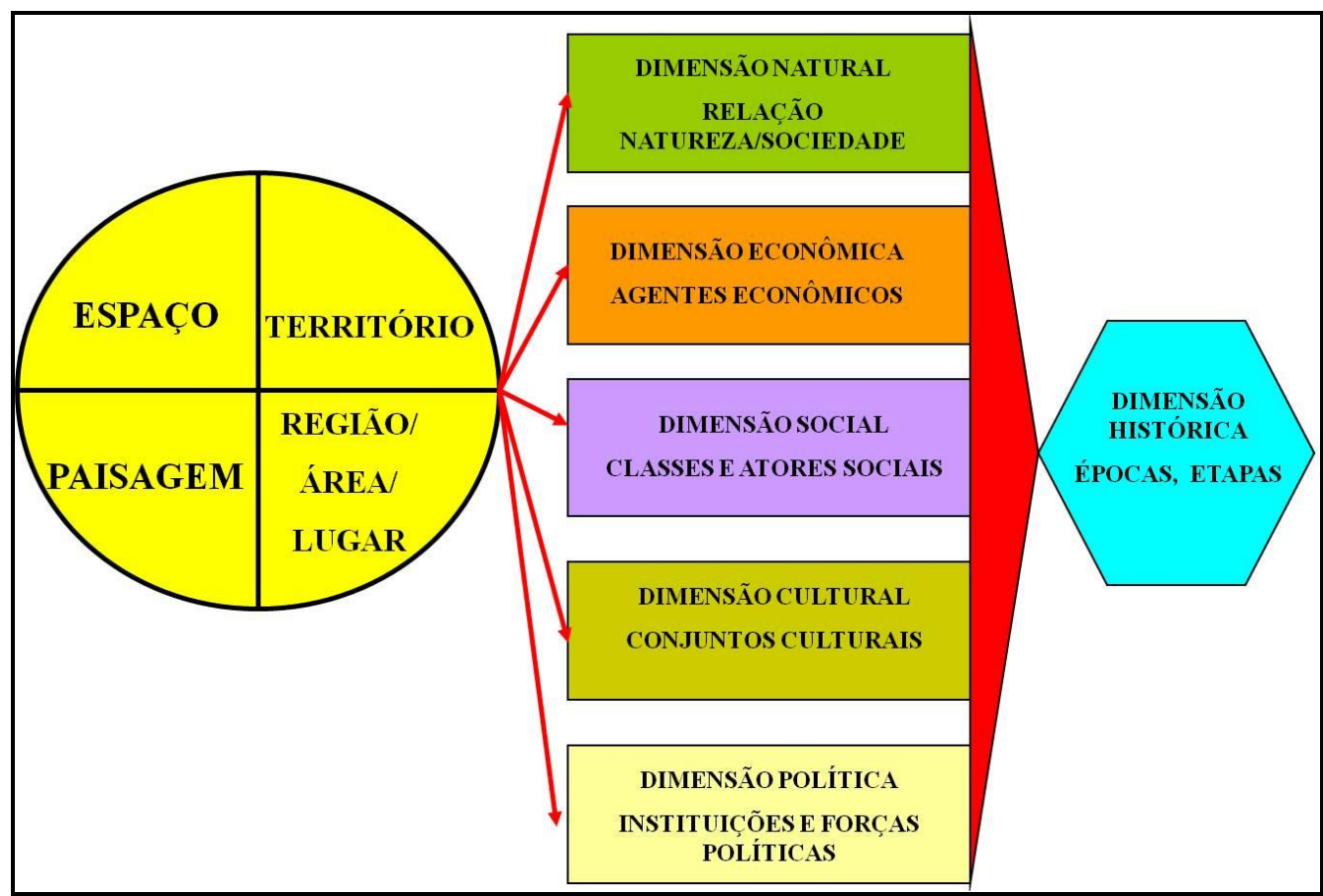

Figura 1: Principais categorias ou unidades de análise geográfica existentes na Geografia e as dimensões consideradas por elas. Fonte: Mateo-Rodríguez (2007). Adaptação: Yuri Tavares Rocha. 


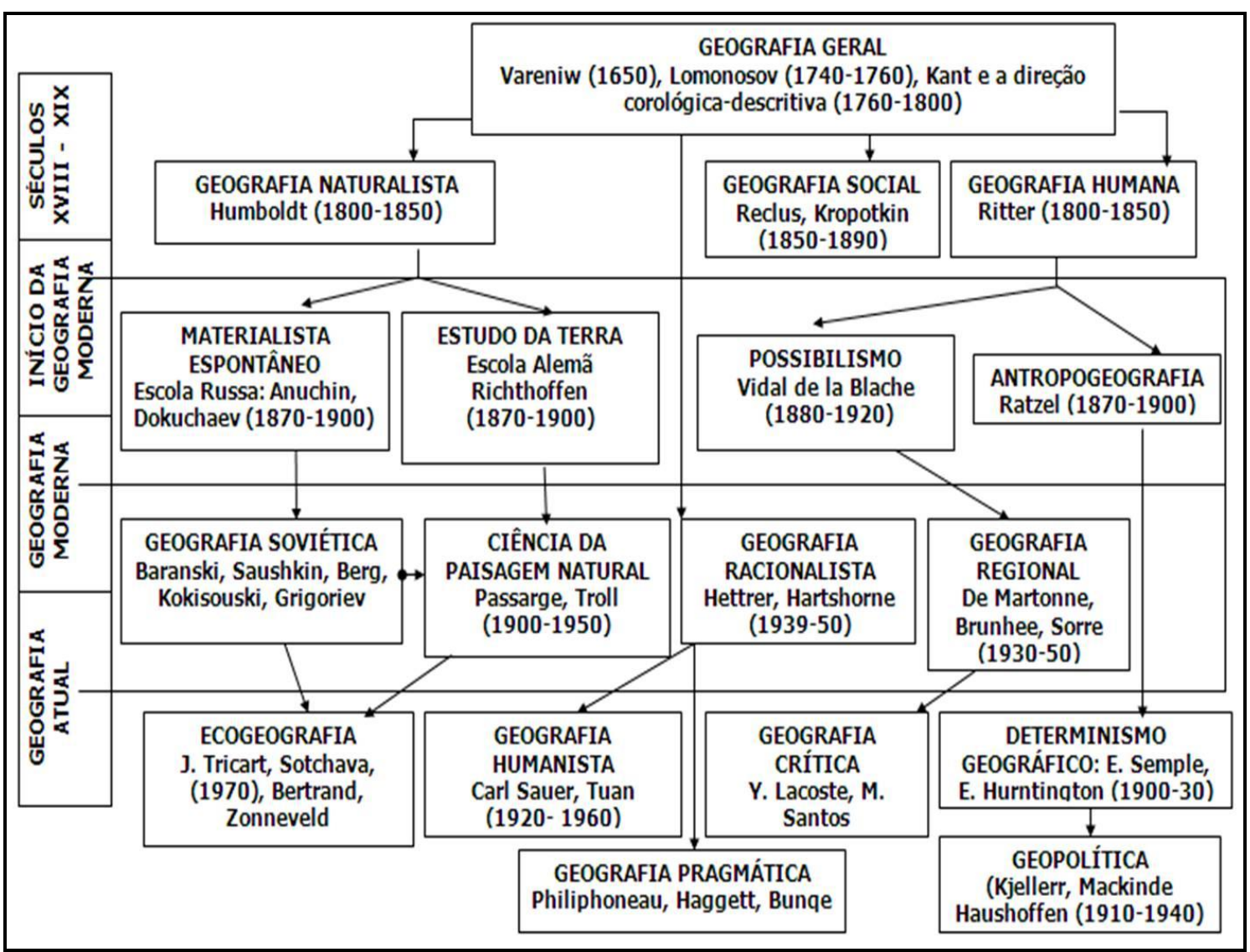

Figura 2: Principais linhas do pensamento geográfico presentes na Geografia. Fonte: Mateo-Rodríguez (2000).

Tais fatos proporcionaram uma riqueza teórico-metodológica muito importante para a ciência geográfica e que se refletiu em cada uma de suas linhas de pensamento, inclusive naquela que adotou a paisagem como unidade de análise geográfica (Figura 3), acarretando o surgimento de diversas escolas da ciência da paisagem. Cada escola é entendida como núcleo ou grupo formado por uma ou mais universidades e ou centros de pesquisa de uma cidade ou país, que deu origem a uma determinada direção dentro dessa ciência, propondo novos problemas e criando novos métodos, com contribuições de vários autores (BOLÓs, 1992).

$\mathrm{Na}$ década de 1990, Felisberto Cavalheiro ${ }^{2}$, professor do Departamento de Geografia/FFLCH/USP, falecido em 2003 e um dos maiores especialistas da área de Ecologia da Paisagem e Planejamento Ambiental no Brasil, analisou apenas as histórias, influências e autores das escolas alemã e americana, as que mais influenciaram os pesquisadores brasileiros, juntamente com a escola francesa (Figura 4).

\footnotetext{
${ }^{2}$ Informação pessoal e material apresentado em aulas e palestras.
} 


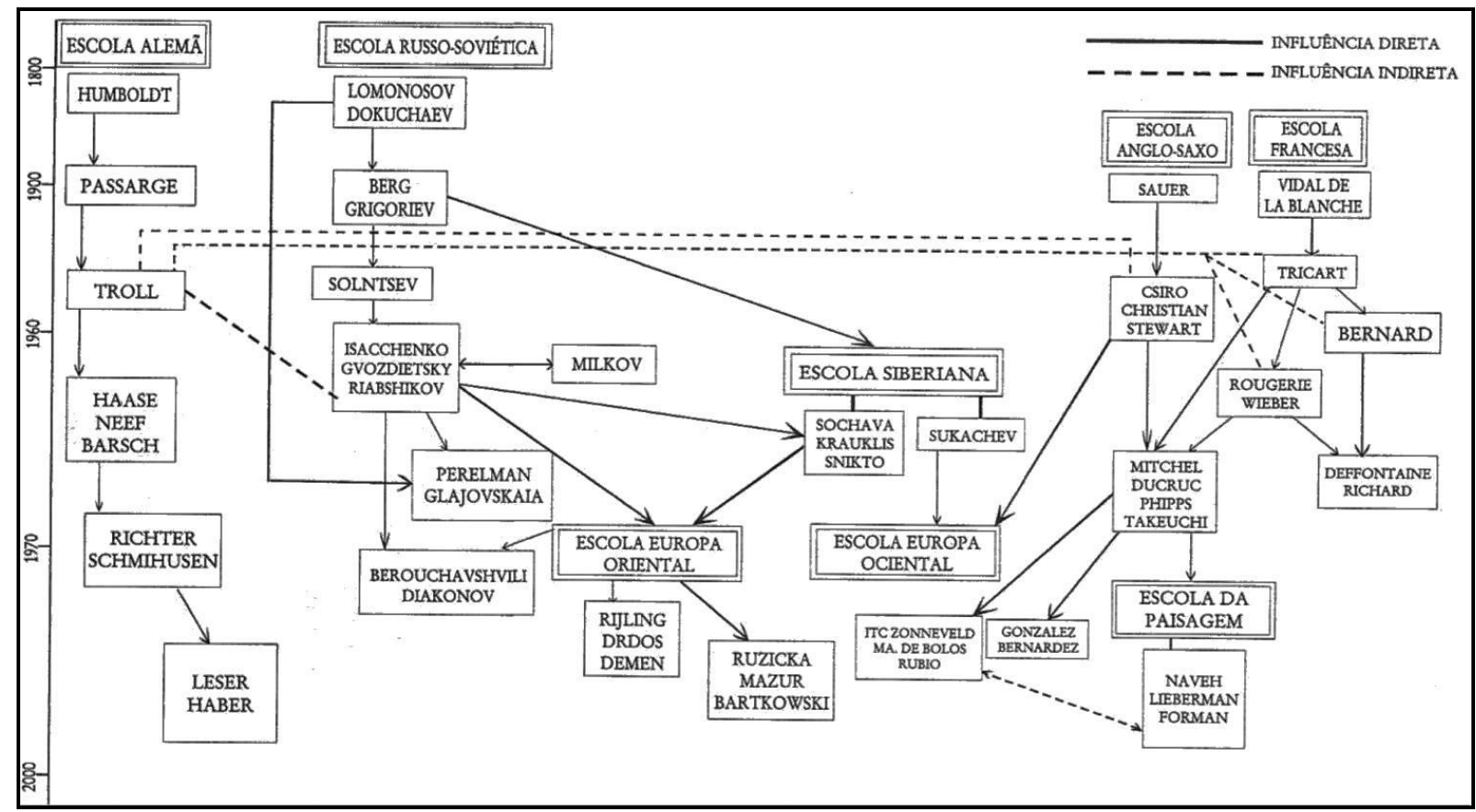

Figura 3: Principais escolas da Ciência da Paisagem, suas influências diretas e indiretas e alguns de seus principais autores. Fonte: Mateo-Rodríguez (2000).

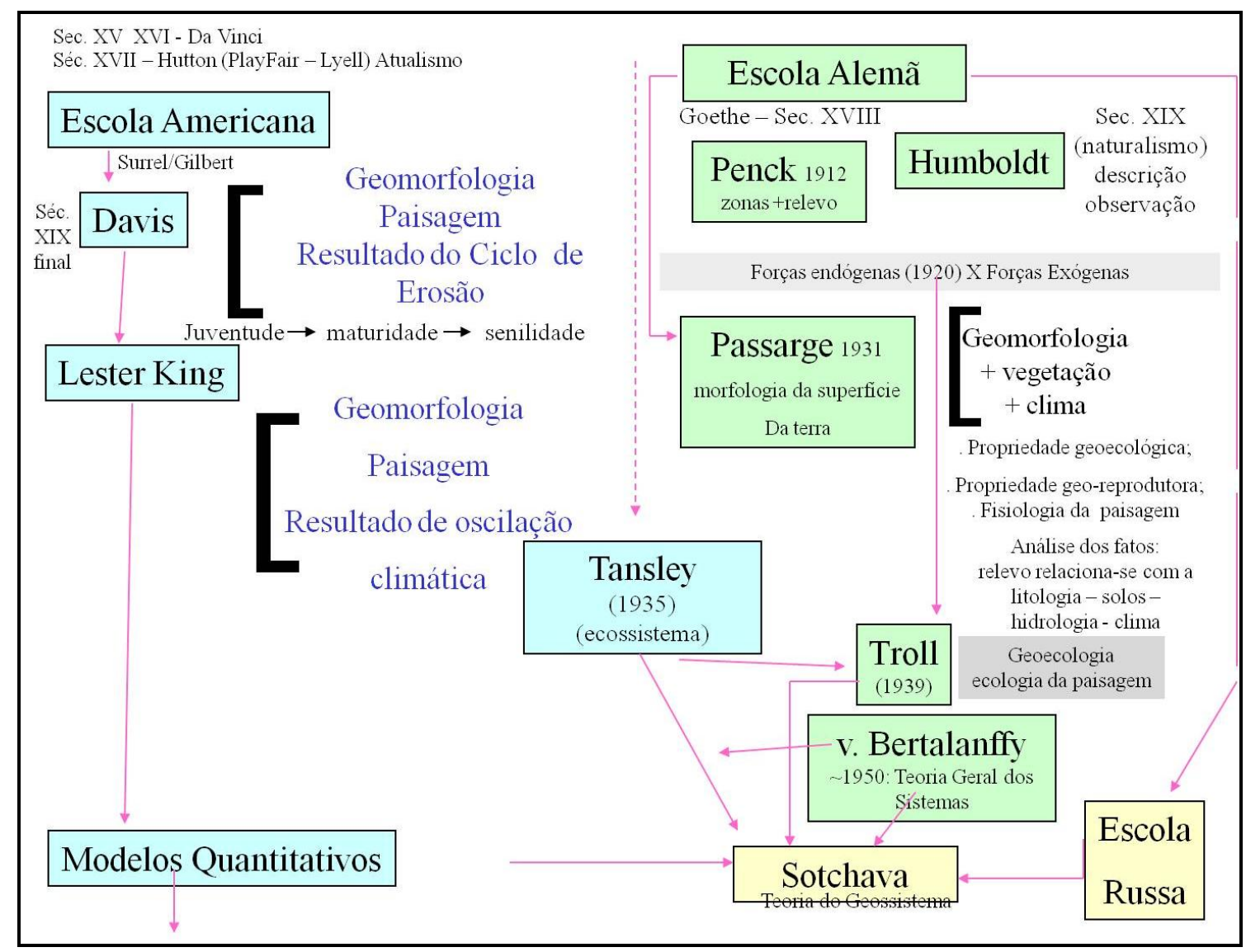

Figura 4: Principais influências e autores das escolas alemã e americana da Teoria Geográfica da Paisagem. Fonte: Felisberto Cavalheiro ${ }^{1}$. Adaptação: Andrea Presotto. 
Para a ciência geográfica, o conceito de paisagem apresenta diferentes noções e complexidades, o que permitiu o desenvolvimento de diversas abordagens e enfoques (Figura 5), tais como estrutural, funcional, dinâmico-evolutivo, informacional e históricoantropogênico (MATEO-RODRÍGUEZ, 2000).

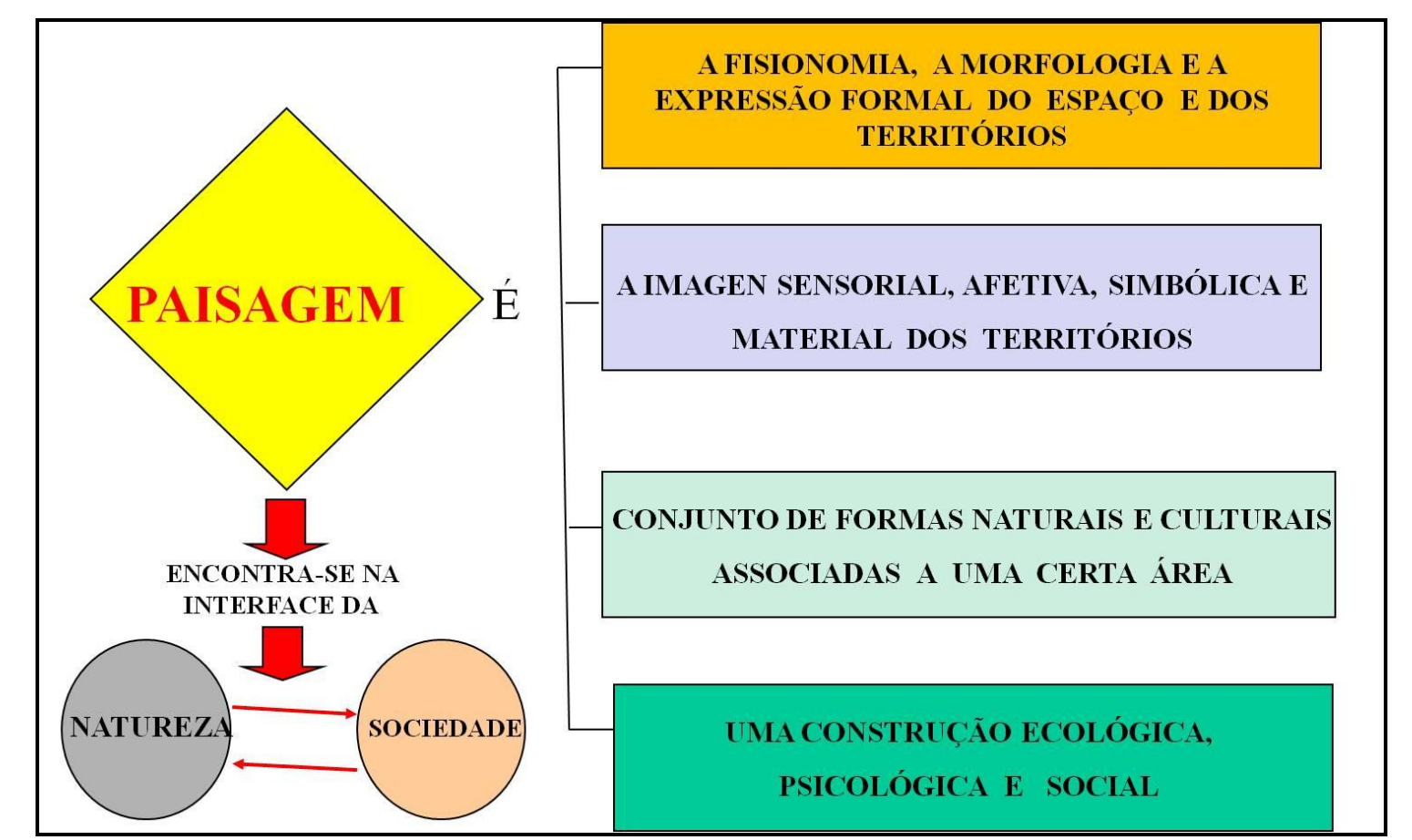

Figura 5: A paisagem e suas diversas noções dentro da Geografia. Fonte: Mateo-Rodríguez (2007). Adaptação: Yuri Tavares Rocha.

São tantos os conceitos existentes de paisagem e apresentados por diversos autores que Gomes (2007) apresentou 11 tipologias de paisagem estabelecidas por Gerhard Hard em 1992, que definem a paisagem como: quadro paisagístico do vivenciado ou vivido; fisionomia de espaços terrestres ou aspectos fisionômicos de microespaços; espaços paisagísticos; espaço terrestre com o conjunto dos elementos que o constitui; estrutura espacial ordenada; ecossistema; meio dos organismos; as relações geográfico-naturais espaciais como adversárias dos grupos humanos; as constantes históricas de recortes espaciais ou espaço terrestre com constantes históricas características; sistemas limitados de interações sociais; e, a fenomenalidade de uma expressão agradável. Gomes (2007) esclareceu que esses conceitos parecem muito próximos por vezes e muito distantes por outras, mas que, em seu conjunto, representam a busca da compreensão didática das 
possíveis associações ligadas à paisagem e à espera de uma discussão interdisciplinar sobre a paisagem.

Objetivando compreender o entendimento sobre paisagem que os alunos do Bacharelado em Geografia do Departamento de Geografia da Faculdade de Filosofia, Letras e Ciências Humanas (FFLCH), da Universidade de São Paulo (USP), possuem antes de cursar a disciplina optativa FLG 437 - Teoria Geográfica da Paisagem, realizou-se aplicação de questionários nas turmas de 2006 a 2011 da referida disciplina sob minha responsabilidade.

A análise dos resultados permitiu comparar a estrutura curricular de cursos de bacharelado em Geografia das universidades estaduais paulistas quanto à categoria de análise geográfica paisagem; verificar a existência de disciplinas que tratam da paisagem antes dos alunos cursarem a disciplina específica no Bacharelado em Geografia da USP; conhecer as principais definições sobre paisagem elaboradas pelos alunos, os autores já conhecidos por eles previamente e as fontes desse conhecimento; e, propor mudanças que valorizem a paisagem como categoria de análise geográfica na formação dos geógrafos pelo Departamento de Geografia/FFLCH/USP.

\section{MATERIAL E PROCEDIMENTOS METODOLÓGICOS}

\section{Questionário}

Um questionário para uma pesquisa científica deve obedecer a alguns requisitos: ser bem estruturado a partir de hipóteses claras; possuir redação objetiva e clara; ter organização lógica; boa apresentação gráfica; e, concisão (MARANGONI, 2005).

Seguindo essas indicações, foi elaborado um questionário e aplicado aos alunos de graduação do Bacharelado em Geografia do Departamento de Geografia/FFLCH/USP, matriculados na disciplina optativa FLG 437 - Teoria Geográfica da Paisagem.

As perguntas elaboradas tiveram por objetivo descobrir quais entendimentos prévios que os alunos, a maioria em final do curso de graduação (oitavo semestre), já tinham adquirido durante o cumprimento de outras disciplinas, tanto obrigatórias quanto optativas; de quais autores eles lembravam que trataram da temática paisagem; e, em quais circunstâncias tiveram contato com os autores citados. As perguntas foram: 1) O que você entende pela 
palavra "paisagem"?; 2) Você conhece algum(ns) autor(es) que tenha(m) escrito sobre “paisagem"? 3) Conheceu o(s) autor(es) em disciplina, livro ou revista científica?

Dessa forma, a aplicação desse questionário permitiu a obtenção de dados quantitativos e qualitativos referentes à paisagem, ambos de igual importância para as análises realizadas nesta pesquisa. Concorda-se com Marangoni (2005, p. 168) sobre a importância do “(...) uso de dados quantitativos independe da corrente filosófica a que pretenda filiar-se o pesquisador; tal uso será necessário ou não dependendo do propósito do estudo e das características do objeto em análise".

\section{Público alvo para a aplicação do questionário}

A aplicação do mesmo questionário foi realizada com os alunos matriculados e presentes no primeiro dia de aula da disciplina optativa FLG 437 - Teoria Geográfica da Paisagem, antes de qualquer explicação da disciplina ou de seu conteúdo programático, nas turmas diurno e noturno da referida disciplina no segundo semestre de 2006 a 2011, totalizando 12 turmas e 302 alunos matriculados. Porém, o número de questionários respondidos foi menor, 200 (Tabela 1), já que alunos matriculados faltaram no primeiro dia de aula, não havendo mais sentido aplicar o questionário a esses alunos em aulas posteriores, já que a disciplina estava com seu conteúdo programático sendo desenvolvido e alterando a situação de se buscar o entendimento prévio dos alunos sobre paisagem. Dados de aproveitamento das turmas participantes da pesquisa também estão na Tabela 1.

Tabela 1: Dados das turmas diurno e noturno da disciplina optativa do Bacharelado em Geografia FLG 437 . Teoria Geográfica da Paisagem, ministrada no segundo semestre de 2006 a 2011 pelo Prof. Dr. Yuri Tavares Rocha, Departamento de Geografia/FFLCH/USP.

\begin{tabular}{cccccccc}
\hline Item analisado & $\mathbf{2 0 0 6}$ & $\mathbf{2 0 0 7}$ & $\mathbf{2 0 0 8}$ & $\mathbf{2 0 0 9}$ & $\mathbf{2 0 1 0}$ & $\mathbf{2 0 1 1}$ & Média \\
\hline $\begin{array}{c}\text { Número de questionários } \\
\text { respondidos }\end{array}$ & 69 & 25 & 31 & 31 & 19 & 25 & $\mathbf{3 4}$ \\
\hline $\begin{array}{c}\text { Número de alunos } \\
\text { matriculados* }\end{array}$ & 79 & 39 & 53 & 46 & 44 & 41 & $\mathbf{5 1}$ \\
\hline Aprovação* & $86 \%$ & $83 \%$ & $81 \%$ & $68 \%$ & $72 \%$ & $62 \%$ & $\mathbf{7 6 \%}$ \\
\hline $\begin{array}{c}\text { Reprovação por nota* } \\
\text { Reprovação por nota e } \\
\text { frequência*, caracterizando } \\
\text { abandono de disciplina }\end{array}$ & $5 \%$ & $4 \%$ & $3,5 \%$ & $6,5 \%$ & $4,5 \%$ & $14 \%$ & $\mathbf{6 \%}$ \\
\hline $\begin{array}{c}\text { Nota média final, excluídas } \\
\text { notas dos reprovados }\end{array}$ & 7,0 & 6,6 & 6,5 & 7,2 & 7,6 & 7,4 & $\mathbf{7 , 1}$ \\
\hline $\begin{array}{c}\text { Nota média final*, incluídas } \\
\text { todas as notas }\end{array}$ & 6,4 & 5,7 & 5,7 & 5,3 & 5,2 & 4,9 & $\mathbf{5 , 5}$ \\
\hline
\end{tabular}


* Sistema Júpiter/USP

Organização: Yuri Tavares Rocha.

\section{Análise dos resultados da aplicação dos questionários}

De acordo com Marangoni (2005), após a aplicação dos questionários, a tabulação dos dados deve ser feita o mais rápido possível, para não se perder detalhes do procedimento adotado e para corrigir eventuais erros de informação. Isso foi adotado e, para cada ano da aplicação do mesmo questionário, a tabulação e análise dos dados foram realizadas na mesma semana da aplicação e os resultados foram apresentados aos próprios alunos participantes da pesquisa na aula seguinte à aplicação do questionário (segunda aula).

Assim, todos os dados de cada ano foram tabulados e analisados separadamente e agrupados para a presente análise, envolvendo apenas cálculos de porcentagem e de médias para os itens analisados. Pelo número de questionários, sua complexidade e os objetivos da pesquisa, adotou-se o tratamento manual dos dados sem a necessidade do uso de equipamentos e programas específicos (MARANGONI, 2005), nem tratamentos estatísticos mais elaborados.

Para a questão 1 (O que você entende pela palavra "paisagem"?), por também tratar da coleta de dados qualitativos, as respostas dos alunos foram analisadas e agrupadas em tipologias definidas a partir das próprias respostas dos alunos das 12 turmas participantes da pesquisa. Foram elaboradas sete tipologias, considerando a paisagem como: 1) Alcance do olhar, visível, cenário; 2) Resultado da interação dos materiais e elementos que a compõem; 3) Resultado da interação dinâmica sociedade-natureza; 4) Categoria de análise geográfica, estudo do meio ou componente do espaço, com interações antrópicas; 5) Algo que é observado, percebido, interpretado ou vivido; 6) Lugar ou fisionomia do lugar com variação de aspectos físicos no tempo; e, 7) Sistêmica, integrada. As respostas que não puderam ser agrupadas nas referidas tipologias e que surgiram abaixo de $1 \%$ cada foram reunidas no item "Outras respostas". Alguns alunos apresentaram mais de uma resposta e todas foram analisadas e tabuladas.

Para a questão 2 (Você conhece algum(ns) autor(es) que tenha(m) escrito sobre "paisagem"?), todos os autores citados pelos alunos das 12 turmas participantes da pesquisa foram considerados, não se analisando se realmente eles são ou não autores que tenham 
escrito ou pesquisado temáticas ligadas à paisagem. As respostas que não citaram nenhum autor foram reunidas no item "Não citou".

Para a questão 3 (Conheceu o(s) autor(es) em disciplina, livro ou revista científica?), as respostas dos alunos das 12 turmas participantes da pesquisa foram tabuladas e agrupadas. As respostas que não citaram nenhuma dessas fontes de informação foram reunidas no item "Não citou".

A paisagem na estrutura curricular do Bacharelado em Geografia das universidades públicas paulistas

Na Universidade de São Paulo, o único curso de bacharelado e licenciatura em Geografia é oferecido pelo Departamento de Geografia, da Faculdade de Filosofia, Letras e Ciências Humanas. A estrutura curricular do Bacharelado em Geografia é composta por 27 disciplinas obrigatórias e 56 disciplinas optativas eletivas, além de 18 disciplinas optativas livres, oferecidas por outros Departamentos da Universidade ${ }^{3}$. Entre todas as disciplinas oferecidas, a única que apresenta a palavra paisagem em sua denominação é a FLG 437 Teoria Geográfica da Paisagem, oferecida no oitavo período como disciplina optativa eletiva (Figura 6). Parte do histórico desta disciplina foi descrito por Conti (2001).

Na Universidade Estadual Paulista "Júlio de Mesquita Filho" (Unesp), o curso de bacharelado e licenciatura em Geografia é oferecido em três unidades: Ourinhos, Presidente Prudente e Rio Claro ${ }^{4}$. No Campus Experimental de Ourinhos, a grade curricular do curso de Bacharelado em Geografia com ênfase em Climatologia apresenta 29 disciplinas obrigatórias, cinco disciplinas complementares obrigatórias e 15 disciplinas optativas ${ }^{5}$. Entre todas as disciplinas, a única que apresenta a palavra paisagem em sua denominação é a Teoria da Paisagem, oferecida no segundo semestre do quarto ano, como disciplina optativa eletiva (Figura 7).

\footnotetext{
${ }^{3}$ Grade curricular do Bacharelado em Geografia, da Faculdade de Filosofia, Letras e Ciências Humanas, da Universidade de São Paulo. Disponível em: https://uspdigital.usp.br/jupiterweb/listarGradeCurricular?codcg $=8 \&$ codcur $=8021 \&$ codhab $=101 \&$ tipo $=\mathrm{N}$. Acesso em 26 de outubro de 2012.

${ }^{4}$ Curso de Geografia na Universidade Estadual Paulista "Júlio de Mesquita Filho" (Unesp). Disponível em: http://www.unesp.br/guia/geografia.php. Acesso em 28 de outubro de 2012

${ }^{5}$ Grade curricular do Bacharelado em Geografia do Campus Experimental de Ourinhos/Unesp. Disponível em: http://www.ourinhos.unesp.br/Home/Graduacao/geografia/projeto_pedagogico.pdf. Acesso em 28 de outubro de 2012.
} 


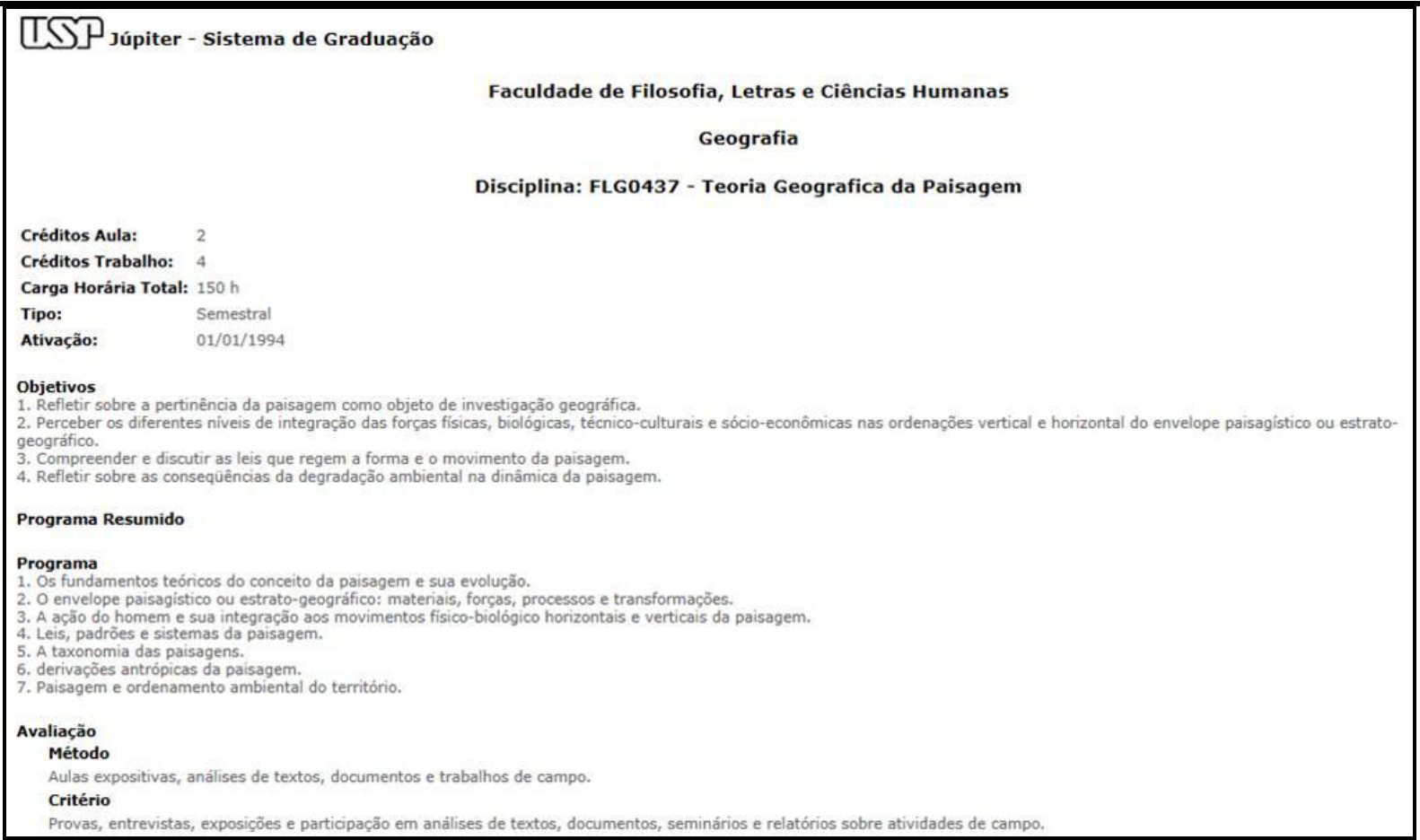

Figura 6: Parte da ementa da disciplina optativa eletiva FLG 437 - Teoria Geográfica da Paisagem, oferecida ao Bacharelado em Geografia, Departamento de Geografia/FFLCH/USP. Fonte:

https://uspdigital.usp.br/jupiterweb/obterDisciplina?sgldis=FLG0437\&codcur=8021\&codhab=101\&print=true.

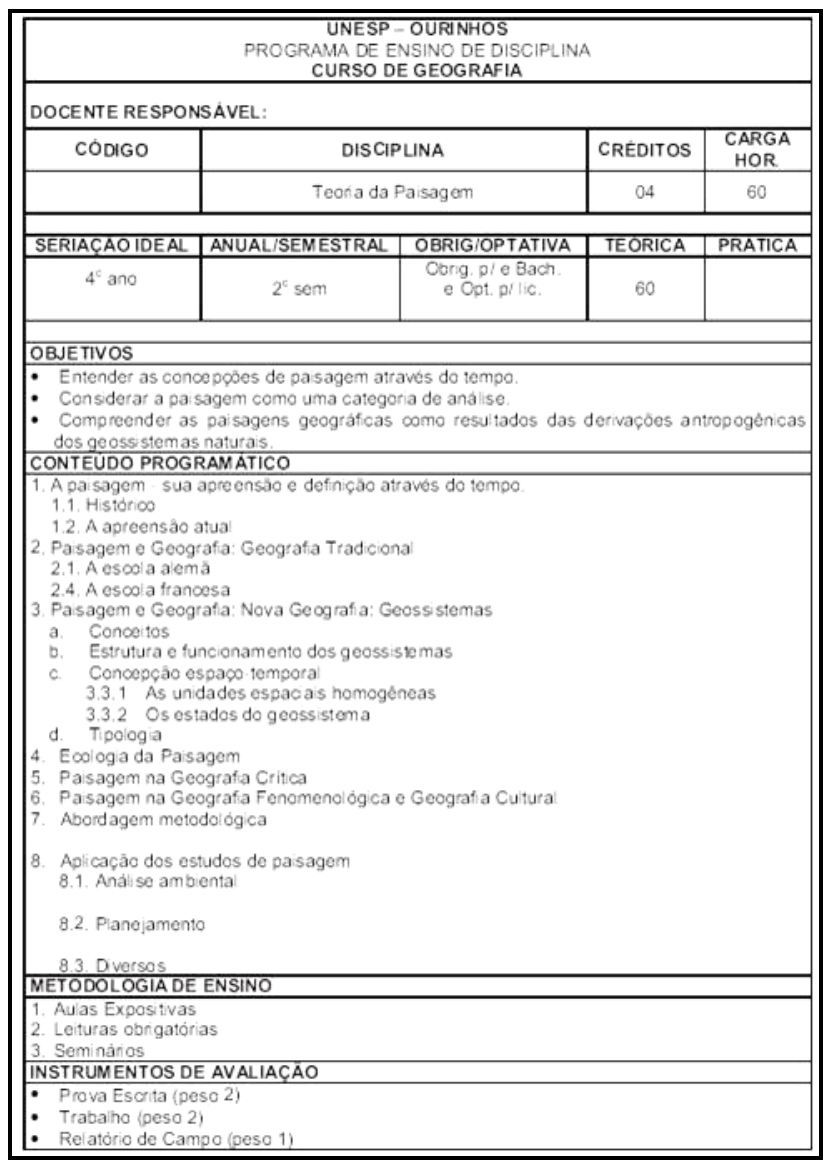

Figura 7: Parte da ementa da disciplina optativa eletiva Teoria da Paisagem, oferecida ao Bacharelado em Geografia, Campus Experimental de Ourinhos/ Unesp. Fonte:

http://www.ourinhos.unesp.br/Home/Graduacao/geografia/projeto pedagogico.pdf. 
No Campus de Presidente Prudente/Unesp, na Faculdade de Ciências e Tecnologia, a grade curricular do Bacharelado em Geografia possui 29 disciplinas obrigatórias, cinco disciplinas complementares obrigatórias e 27 disciplinas optativas ${ }^{6}$. Entre as disciplinas, a única que apresenta a palavra paisagem em sua denominação é a 04 - Análise da Paisagem, oferecida no primeiro semestre do quinto ano, como disciplina optativa eletiva (Figura 8).

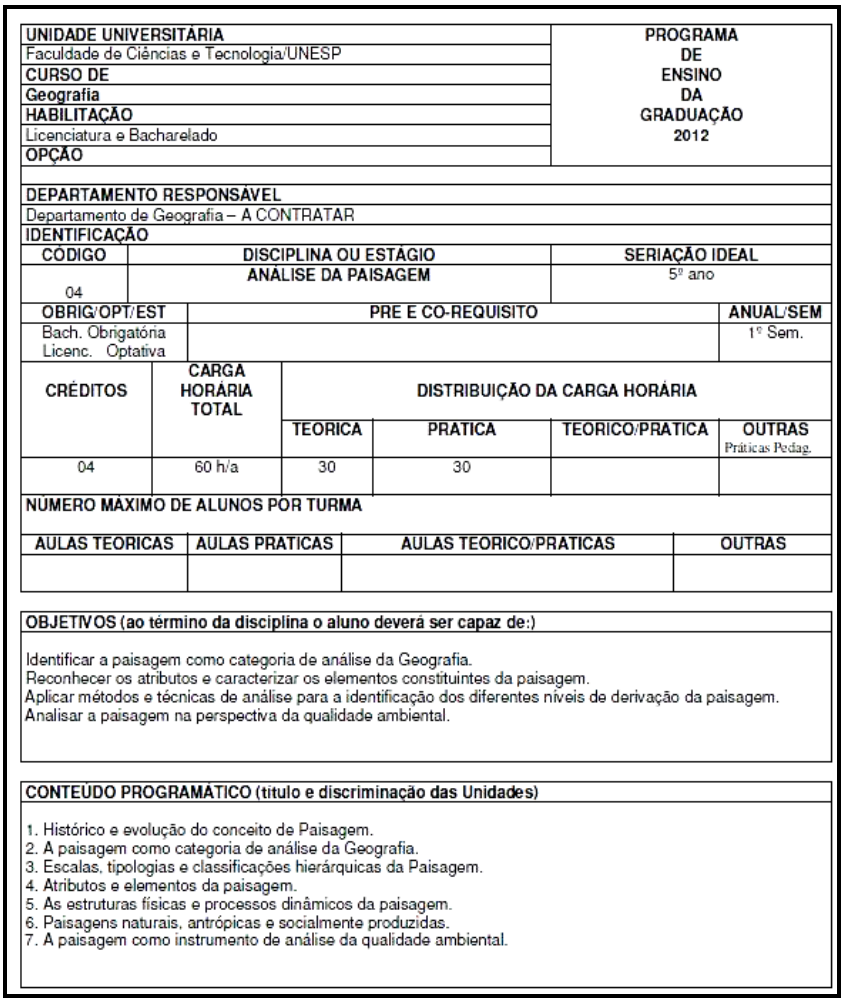

Figura 8: Parte da ementa da disciplina optativa eletiva 04 - Análise da Paisagem, oferecida ao Bacharelado em Geografia, Faculdade de Ciências e Tecnologia/Presidente Prudente/Unesp. Fonte:

http://www.fct.unesp.br/Home/Graduacao/Geografia/analise-da-paisagem.pdf.

No Campus de Rio Claro/Unesp, no Instituto de Geociências e Ciências Exatas, está o mais antigo e tradicional curso de bacharelado e licenciatura Geografia da Unesp, cujo bacharelado permite a formação regular ou com ênfase em Análise Ambiental e Geoprocessamento ou com ênfase em Análise Socioespacial e Planejamento Territorial. A grade curricular do bacharelado na modalidade integral regular é composta por 34 disciplinas obrigatórias; as grades dos bacharelados com ênfase em Análise Ambiental e Geoprocessamento e em Análise Socioespacial e Planejamento Territorial possuem 36 disciplinas obrigatórias cada, com disciplinas diferentes nos terceiro e quarto anos; para as três modalidades, existem 52 disciplinas optativas ${ }^{7}$. Entre todas as disciplinas, há duas que

\footnotetext{
6 Grade curricular do Bacharelado em Geografia do Campus de Presidente Prudente/Unesp. Disponível em: http://www2.fct.unesp.br/cursos/geografia/proj_pedag_geo/projeto_pedagogico_geografia.pdf. Acesso em 28 de outubro de 2012.

7 Grade curricular do Bacharelado Integral em Geografia do Campus de Rio Claro/Unesp. Disponível em: http://www.rc.unesp.br/igce/graduacao/geografia_integral/GEO.html. Acesso em 28 de outubro de 2012.
} 
apresentam a palavra paisagem em sua denominação: a disciplina obrigatória GEG 3454 -

Análise da Paisagem (Figura 9), oferecida no quarto ano para o bacharelado com ênfase em

Análise Ambiental e Geoprocessamento; e, a disciplina optativa GEG 3565 - Análise da

Paisagem: estudos de casos (Figura 10), oferecida também no quarto ano para todos os

bacharelados.

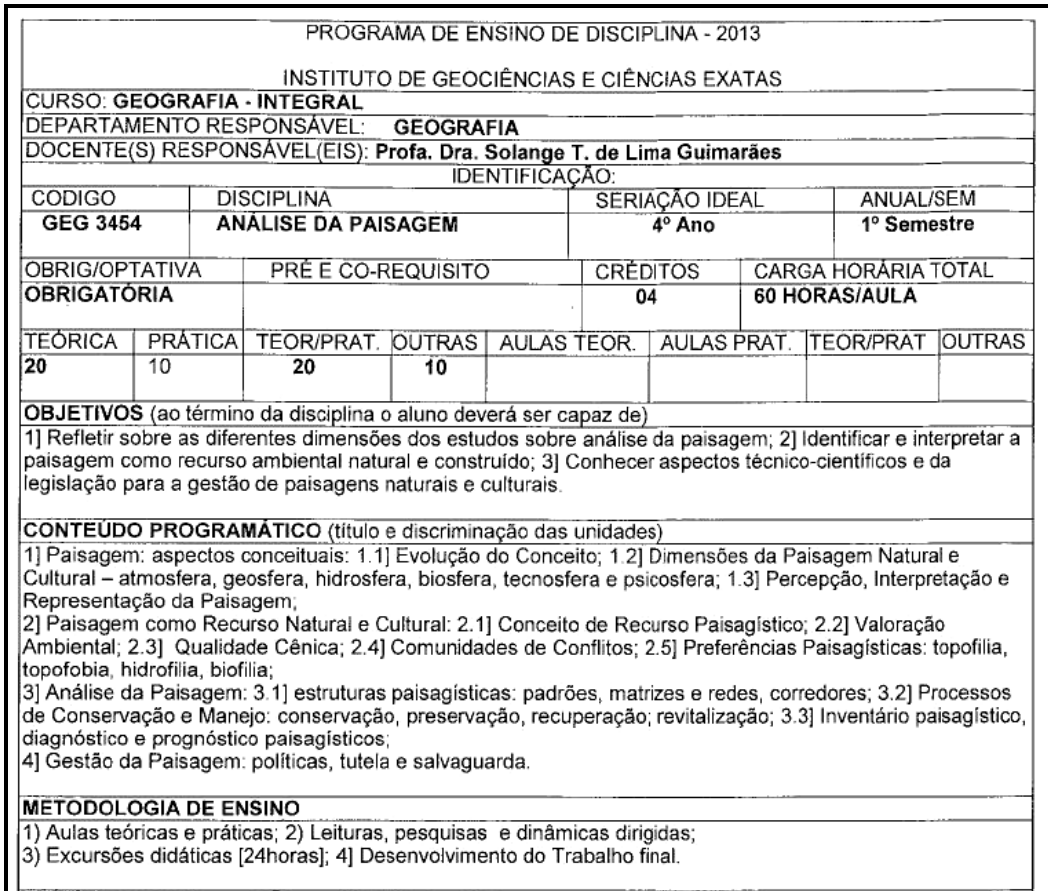

Figura 9: Parte da ementa da disciplina obrigatória GEG 3454 - Análise da Paisagem, oferecida ao Bacharelado em Geografia com ênfase em Análise Ambiental e Geoprocessamento, Instituto de Geociências e Ciências

Exatas, Rio Claro/Unesp. Fonte:

http://www.rc.unesp.br/igce/graduacao/geografia_integral/4-\%20Ano\%20BACH\%20com\%20enfase\%20AAeG/ GEG3454.pdf

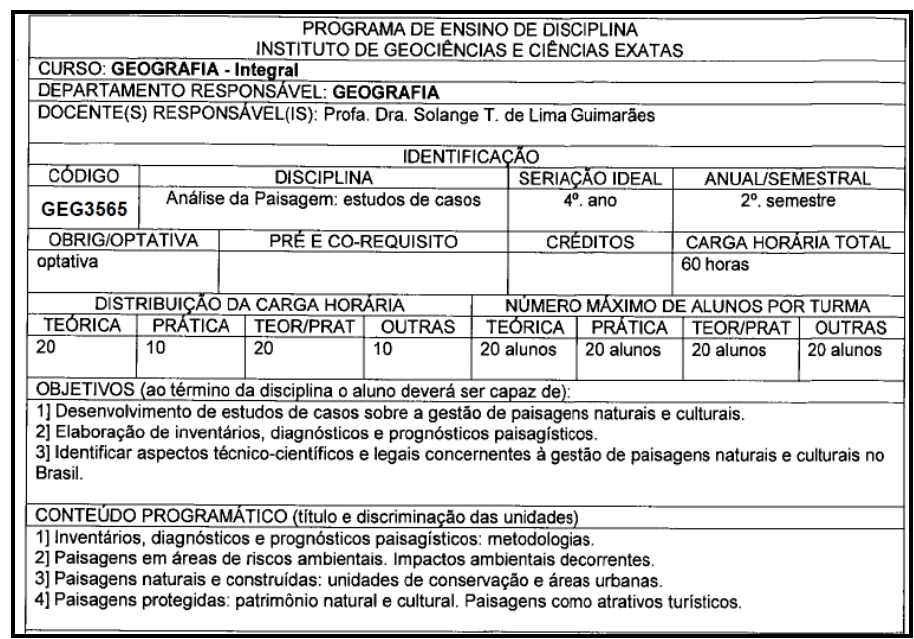

Figura 10: Parte da ementa da disciplina optativa GEG 3565 - Análise da Paisagem: estudos de casos, oferecida para todos os bacharelados em Geografia, Instituto de Geociências e Ciências Exatas, Rio Claro/Unesp. Fonte: http://www.rc.unesp.br/igce/graduacao/geografia integral/Optativas/GEG3565.pdf ). 
$\mathrm{Na}$ Universidade Estadual de Campinas (Unicamp), o único curso de bacharelado e

licenciatura em Geografia é oferecido pelo Instituto de Geociências e pelo seu

Departamento de Geografia. A estrutura curricular do Bacharelado Diurno é composta por

21 disciplinas obrigatórias do Núcleo Comum Ciências da Terra e por 26 disciplinas obrigatórias do Núcleo Bacharelado Diurno, além de 21 disciplinas optativas ${ }^{8}$. Entre todas as disciplinas, não há nenhuma com a palavra paisagem em sua denominação.

\section{RESULTADOS E DISCUSSÃO}

\section{Paisagem e estrutura curricular}

Comparando-se as estruturas curriculares dos bacharelados em Geografia das universidades estaduais paulistas, USP e Unesp possuem uma disciplina obrigatória e ou optativa que apresenta a paisagem em sua denominação; a Unicamp não possui nenhuma (Tabela2).

Tabela 2: Resumo das estruturas curriculares dos bacharelados em Geografia, das universidades estaduais paulistas: Universidade de São Paulo (USP), Universidade Estadual Paulista “Júlio de Mesquita Filho” (Unesp) e Universidade Estadual de Campinas (Unicamp).

\begin{tabular}{cccccc}
\hline \multirow{2}{*}{ Item analisado } & USP & Unesp & \multirow{2}{*}{ Unicamp } \\
\cline { 3 - 5 } & OR & PP & RC & Un \\
\hline Disciplinas obrigatórias & 27 & 29 & 29 & 34 & 47 \\
\hline Disciplinas obrigatórias complementares & - & 5 & 5 & 2 & - \\
\hline Disciplinas optativas eletivas & 56 & 15 & 27 & 52 & 21 \\
\hline $\begin{array}{c}\text { Disciplina obrigatória com paisagem em } \\
\text { sua denominação }\end{array}$ & - & - & - & $1 *$ & - \\
\hline $\begin{array}{c}\text { Disciplina optativa eletiva com paisagem } \\
\text { em sua denominação }\end{array}$ & 1 & 1 & 1 & 1 & - \\
\hline
\end{tabular}

Obs.: OR - Campus Experimental de Ourinhos; PP - Campus de Presidente Prudente; RC - Campus de Rio Claro

* Disciplina obrigatória para Bacharelado em Geografia com ênfase em Análise Ambiental e Geoprocessamento Fontes:

https://uspdigital.usp.br/jupiterweb/listarGradeCurricular?codcg=8\&codcur=8021\&codhab $=101 \&$ tipo=N; http://www.ourinhos.unesp.br/Home/Graduacao/geografia/projeto pedagogico.pdf; http://www2.fct.unesp.br/cursos/geografia/proj pedag geo/projeto pedagogico geografia.pdf; http://www.rc.unesp.br/igce/graduacao/geografia_integral/GEO.html. Organização: Yuri Tavares Rocha

O Bacharelado em Geografia com ênfase em Análise Ambiental e Geoprocessamento, do Instituto de Geociências e Ciências Exatas/campus Rio Claro/Unesp, é o único que possui

8 Grade curricular do Bacharelado Diurno em Geografia do Instituto de Geociências/Unicamp. Disponível em: http://www.ige.unicamp.br/site/htm/16. php?nivel=6\&curso=1\&area=2\&local=3

http://www.ige.unicamp.br/site/htm/16.php?nivel=6\&curso=3\&area=2\&local=3. Acesso em 28 de outubro de 2012. 
uma disciplina obrigatória (GEG 3454 - Análise da Paisagem) que trata da paisagem como unidade de análise geográfica Os outros bacharelados apresentam apenas disciplinas optativas eletivas (FLG 437 - Teoria Geográfica da Paisagem, Teoria da Paisagem e GEG 3565 - Análise da Paisagem: estudos de casos). Isso significa que apenas em Rio Claro/Unesp os alunos da graduação com essa ênfase têm a paisagem valorizada em sua formação, participando e contribuindo em igualdade com as demais unidades de análise geográfica. Nos outros bacharelados da Unesp e no da USP, somente os alunos que optam pela disciplina é que têm sua formação completada com conhecimentos a respeito da paisagem. Considerando-se apenas as disciplinas optativas eletivas, a disciplina que trata de paisagem representa apenas $1,8 \%$ do total das oferecidas no bacharelado da USP; $6,7 \%$ do total das oferecidas no bacharelado do Campus Experimental de Ourinhos/Unesp; 3,7\% do total das oferecidas no bacharelado do Campus de Presidente Prudente/Unesp; e, 1,9\% do total das oferecidas no bacharelado do Campus de Rio Claro/Unesp. Isso significa que a menor oferta de disciplinas optativas aumenta a contribuição relativa da disciplina sobre paisagem e, consequentemente, tem maior probabilidade de ter um maior número de alunos que teriam maiores conhecimentos sobre paisagem em sua formação. Isso é o que ocorre no bacharelado do Campus Experimental de Ourinhos/Unesp. O oposto ocorre no bacharelado da USP, que também possui mais 18 disciplinas optativas livres que, se forem consideradas nesse cálculo, a disciplina que trata de paisagem representaria menos ainda: 1,3\% do total das oferecidas.

Quanto à carga horária da disciplina obrigatória ou eletiva que trata de paisagem, todas as oferecidas nos bacharelados da Unesp apresentam 60 horas de aula (quatro créditos) e a do bacharelado da USP apresenta a metade, 30 horas de aula (dois créditos), mas possui quatro créditos de trabalho (120 horas).

Por último, vale ressaltar que todos os bacharelados oferecem a disciplina obrigatória ou eletiva que trata de paisagem no último semestre ou ano do curso, significando que os alunos precisam de conhecimentos geográficos prévios para ter contato com a paisagem como unidade de análise geográfica, fato que garante o total aproveitamento da referida disciplina na formação desses futuros geógrafos.

\section{Questão 1: O que você entende pela palavra "paisagem"?}


As respostas dos alunos das 12 turmas participantes da pesquisa foram agrupadas em sete tipologias; as respostas que não puderam ser agrupadas e que surgiram abaixo de $1 \%$ cada foram reunidas no item "Outras respostas" (Tabela 3).

Tabela 3: Repostas dos alunos das 12 turmas participantes da pesquisa dadas à questão "O que você entende pela palavra 'paisagem'?", turmas diurno e noturno da disciplina optativa FLG 437 - Teoria Geográfica da Paisagem do Bacharelado em Geografia, ministrada nos segundos semestres de 2006 a 2011 pelo Prof. Dr. Yuri Tavares Rocha, Departamento de Geografia/FFLCH/USP.

\begin{tabular}{cccccccc}
\hline Paisagem é & $\mathbf{2 0 0 6}$ & $\mathbf{2 0 0 7}$ & $\mathbf{2 0 0 8}$ & $\mathbf{2 0 0 9}$ & $\mathbf{2 0 1 0}$ & $\mathbf{2 0 1 1}$ & Média \\
\hline $\begin{array}{c}\text { Alcance do olhar, visível, } \\
\text { cenário }\end{array}$ & $33 \%$ & $55 \%$ & $33 \%$ & $23 \%$ & $24 \%$ & $20 \%$ & $\mathbf{3 2 \%}$ \\
\hline
\end{tabular}

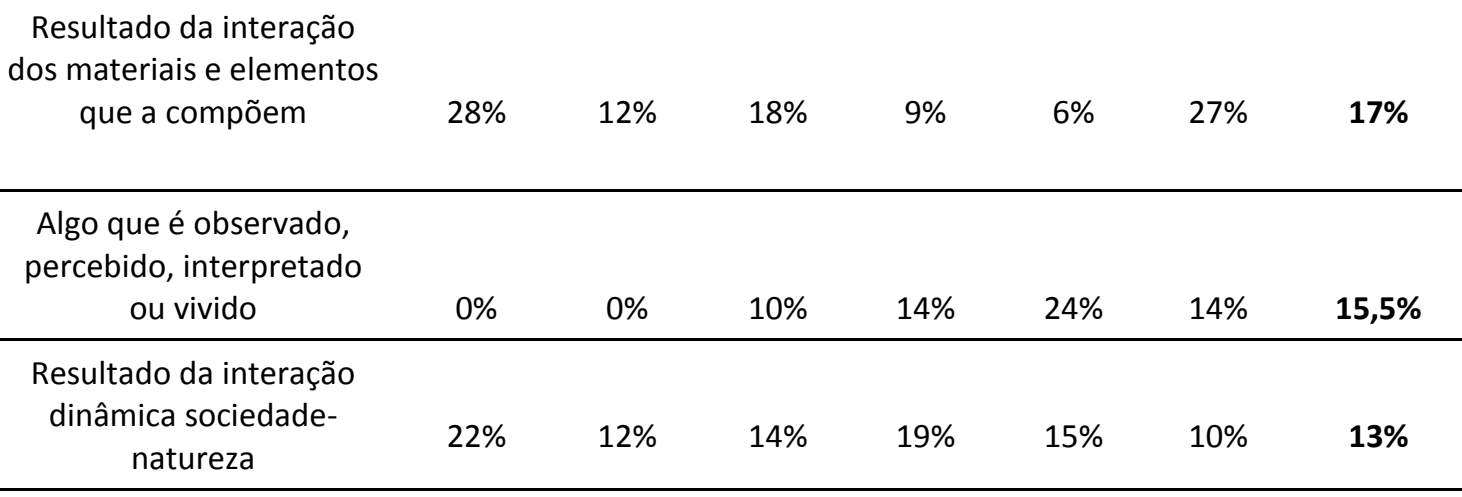

Categoria de análise geográfica, estudo do meio ou componente do espaço, com interações antrópicas

\begin{tabular}{cccccccc}
$\begin{array}{c}\text { Lugar ou fisionomia do } \\
\text { lugar com variação de } \\
\text { aspectos físicos no tempo }\end{array}$ & $2 \%$ & $4 \%$ & $2 \%$ & $12 \%$ & $0 \%$ & $10 \%$ & $\mathbf{4 , 4 \%}$ \\
\hline Sistêmica, integrada & $0 \%$ & $0 \%$ & $7 \%$ & $3 \%$ & $3 \%$ & $0 \%$ & $\mathbf{4 \%}$ \\
\hline Outras respostas & $8 \%$ & $1 \%$ & $6 \%$ & $5 \%$ & $13 \%$ & $19 \%$ & $\mathbf{9 \%}$ \\
\hline
\end{tabular}

Organização: Yuri Tavares Rocha

As respostas representam as concepções prévias sobre paisagem que os alunos obtiveram em outras disciplinas já cursadas no bacharelado da USP e em suas experiências acadêmicas pessoais.

A resposta que a paisagem é o que está ao "alcance do olhar, o que é visível e um cenário" foi a mais citada em quase todos os anos (média de 32\%) e representa a concepção sobre paisagem do senso comum, menos elaborada em termos geográficos.

Também está presente em dicionários da língua portuguesa: 
$\checkmark$ "paisagem, s. f. Espaço de território que se abrange num lance de vista; gênero literário ou de pintura que descreve ou representa o campo ou cenas campestres" (BUENO, 1962, p. 894);

$\checkmark$ "paisagem, S. f. 1. Espaço de terreno que se abrange num lance de vista; 2. Pintura, gravura ou desenho que representa uma paisagem natural ou urbana" (FERREIRA, 1988, p. 474);

$\checkmark$ "paisagem, pai.sa.gem, sf (fr paysage) 1 Extensão de território que se abrange num lance de vista. 2 Desenho, quadro que representa um lugar campestre. 3 Trecho literário de assunto campestre. 4 Inform Orientação de uma página ou pedaço de papel onde a borda mais longa é a horizontal" (MICHAELIS, 2007).

Percebe-se nos dicionários citados que outros significados foram adicionados à palavra paisagem com o passar do tempo, mas o relacionado à visão e ao olhar continuou sendo o primeiro significado apresentado.

Essa resposta mais citada também representa uma possibilidade de definição em algumas abordagens e para alguns autores como, por exemplo, para Meining (1979): a paisagem é definida por nossa visão e interpretada por nossas mentes; e, para Burle Marx (1987): a paisagem é todo e qualquer ambiente de nosso território ou domínio visual.

Também aparece na comparação entre unidades espaciais de análise geográfica como, por exemplo, em Santos (2006, p. 66-67): “Paisagem e espaço não são sinónimos. A paisagem é o conjunto de formas que, num dado momento, exprimem as heranças que representam as sucessivas relações localizadas entre home e natureza. $O$ espaço são essas formas mais a vida que as anima. (...) A rigor, a paisagem é apenas a porção da configuração territorial que é possível abarcar com a visão". Santos (1988, p. 61) explicou que "tudo aquilo que vemos, o que nossa visão alcança, é a paisagem. Esta pode ser definida como o domínio do visível, aquilo que a vista abarca. Não é formada apenas de volumes, mas também de cores, movimentos, odores, sons, etc."

Após a resposta mais citada, há outras quatro na sequência que foram citadas em torno de $15 \%$. A resposta que a paisagem é o "resultado da interação dos materiais e elementos que a compõem" (17\%) já apresenta uma elaboração geográfica maior e que nos remete a uma das primeiras concepções paisagísticas do século XIX, feita por Alexander von Humboldt, que entendia que a paisagem é um conjunto de formas que caracteriza um determinado setor da 
superfície terrestre e que é importante a compreensão das relações entre os elementos que formam um todo animado por determinadas forças interiores (BOLÓS, 1992).

A resposta que a paisagem é "algo que é observado, percebido, interpretado ou vivido" $(15,5 \%)$ nos remete, em certa medida, também à primeira resposta, uma vez que o sentido da visão é o primeiro e mais utilizado pelo observador para perceber e entender a paisagem. Também representa uma das abordagens possíveis no estudo da paisagem e é desenvolvida por autores que consideram a paisagem como o quadro paisagístico do vivenciado ou vivido, sendo um "recorte espacial de uma determinada parcela da superfície da terra, cujos atributos naturais e paisagísticos evocam sentimentos de amenidades e recordações vitais, capazes de rápida apreensão e descrição pelo observador" (HARD, 1992 apud GOMES, 2007, p. 32).

A resposta que a paisagem é "resultado da interação dinâmica sociedade-natureza" (13\%) representa uma das frentes de ação da ciência geográfica apontada por Conti (1998) e já citada neste artigo. Há uma abordagem que considera que a paisagem varia conforme suas características fisiográficas e ambientais e de acordo com o impacto histórico que sofre, constituindo-se em reflexo dos sistemas natural e social (LAURIE, 1983). Assim, a paisagem pode ser considerada de três formas que, dentro da metodologia científica, correspondem a três modos de pesquisa: fisionômico, ecológico e histórico (BOBEK; SCHMITHÜSEN, 1949).

A resposta que a paisagem é "categoria de análise geográfica, estudo do meio ou componente do espaço, com interações antrópicas" (12\%) reforça que a paisagem é uma das unidades espaciais de análise geográfica, juntamente com espaço, região, território e lugar, além de ressaltar a presença antrópica na paisagem. Alguns críticos da Teoria Geográfica da Paisagem alegam que essa categoria geográfica enfoca apenas a parte física ou da natureza, sem considerar o antrópico ou a sociedade. Isso não procede, como lembrou Bertrand (1972): a paisagem é o resultado da combinação dinâmica dos elementos físicos, biológicos e antrópicos e que integra o natural e todas as simplificações da ação antrópica. Monteiro (2000) também reforçou que a paisagem é sempre resultante da integração dinâmica dos elementos de suporte e cobertura, os físicos, biológicos e antrópicos, que organizam um sistema, um conjunto em constante evolução.

A resposta que a paisagem é o "lugar ou fisionomia do lugar com variação de aspectos físicos no tempo" $(4,4 \%)$ representa uma tentativa de união das categorias paisagem e lugar. Alguns autores que consideram a paisagem como "algo que é observado, percebido, 
interpretado ou vivido", também trabalham como essa abordagem, como Brunet (1974), Schama (1996) e Tuan (1980), entre outros.

A resposta que a paisagem "é sistêmica, integrada" (4\%) apresenta uma elaboração geográfica e um detalhamento maior de um das abordagens existentes no estudo da paisagem, desenvolvida por diferentes escolas, principalmente alemã (TROLL, 1950), russa (SOCHAVA, 1978) e francesa (BERTRAND, 1972; TRICART, 1979). Humboldt já definiu, no século XIX, que a paisagem é integrada, cíclica e dinâmica (BOLÓS, 1992).

\section{Questão 2: Você conhece algum(ns) autor(es) que tenha(m) escrito sobre}

\section{"paisagem"?}

As respostas dos alunos das 12 turmas participantes da pesquisa foram agrupadas nos nomes dos autores citados, não se analisando se realmente eles são ou não autores que tenham escrito ou pesquisado temáticas ligadas à paisagem; as respostas que não citaram nenhum autor foram reunidas no item "Não citou" (Tabela 4).

Tabela 4: Repostas dos alunos das 12 turmas participantes da pesquisa dadas à questão "Você conhece algum(ns) autor(es) que tenha(m) escrito sobre "paisagem"?", turmas diurno e noturno da disciplina optativa FLG 437 - Teoria Geográfica da Paisagem do Bacharelado em Geografia, ministrada nos segundos semestres de 2006 a 2011 pelo Prof. Dr. Yuri Tavares Rocha, Departamento de Geografia/FFLCH/USP.

\begin{tabular}{cccccccc}
\hline Autores citados & $\mathbf{2 0 0 6}$ & $\mathbf{2 0 0 7}$ & $\mathbf{2 0 0 8}$ & $\mathbf{2 0 0 9}$ & $\mathbf{2 0 1 0}$ & $\mathbf{2 0 1 1}$ & Média \\
\hline M. Santos & $26 \%$ & $32 \%$ & $16 \%$ & $14 \%$ & $22 \%$ & $18 \%$ & $\mathbf{2 1 , 3 \%}$ \\
\hline A. N. Ab'Saber & $13 \%$ & $8 \%$ & $8 \%$ & $13 \%$ & $8 \%$ & $6 \%$ & $\mathbf{9 , 7 \%}$ \\
\hline G. Bertrand & $5 \%$ & $8 \%$ & $8 \%$ & $7 \%$ & $8 \%$ & $3 \%$ & $\mathbf{6 , 5 \%}$ \\
\hline J. Tricart & $7 \%$ & $8 \%$ & $4 \%$ & $7 \%$ & $0 \%$ & $3 \%$ & $\mathbf{6 , 2} \%$ \\
\hline C. A. F. Monteiro & $0 \%$ & $0 \%$ & $8 \%$ & $3 \%$ & $4 \%$ & $0 \%$ & $\mathbf{5 , 3 \%}$ \\
\hline Y. F. Tuan & $0 \%$ & $0 \%$ & $4 \%$ & $0 \%$ & $4 \%$ & $9 \%$ & $\mathbf{5 , 7 \%}$ \\
\hline Não citou & $20 \%$ & $20 \%$ & $10 \%$ & $35 \%$ & $46 \%$ & $33 \%$ & $\mathbf{2 7 \%}$ \\
\hline
\end{tabular}

Organização: Yuri Tavares Rocha

Outros 53 autores citados não foram relacionados na Tabela 3 por terem sido citados em menos de $2 \%$ dos questionários. Foram os seguintes: Ancel, Benjamin, Boudelaire, Brunhes, Burle Marx, Carlos, Cavalheiro, Christofoletti, Claval, Conti, Corrêa, De La Blache, Delpoux, De Martonne, De Pablo, Dieter, Diamantino, D. Santos, Dumeau, Forman, George, Godron, Humboldt, Lacoste, Lau, Lencioni, Lynch, Martinelli, Metzger, Monbeig, Moraes, Moreira, Monteiro, Passos, Prado Júnior, Raffestin, Ratzel, Rosendahl, Ross, Rosseau, Rougerie, Salinas, Sauer, Silva, Soia, Sorre, Sochava, Sousa, Troll, Troppmair, Turner, Viadana e Yázigi. 
O autor mais citado pelos alunos foi Santos, com $21,3 \%$, indicando que esse autor foi utilizado e indicado em outras disciplinas e suas obras e textos lidos. Porém, Santos foi um autor com produção dedicada à unidade de análise geográfica denominada espaço, partícipe de outra corrente teórico-metodológica da ciência geográfica, a chamada "Geografia Crítica", na qual Conti (1998) também incluiu o francês Yves Lacoste e o espanhol Horácio Capel. Essa corrente é adotada por muitas disciplinas obrigatórias e optativas eletivas do Bacharelado em Geografia do Departamento de Geografia/FFLCH/USP, predominando a categoria espaço na formação de seus alunos.

Os autores Santos, Ab'Saber e Monteiro foram professores do referido Departamento e formaram muitos mestres e doutores que também se tornarem professores do mesmo Departamento; os dois últimos ministraram disciplinas sobre paisagem e possuem obras dedicadas a essa temática.

\section{Questão 3: Conheceu o(s) autor(es) em disciplina, livro ou revista científica?}

As respostas dos alunos das 12 turmas participantes da pesquisa foram agrupadas nos itens disciplina, livro ou revista científica; as respostas que não citaram nenhum dos itens foram reunidas no item "Não citou" (Tabela 5).

Tabela 5: Repostas dos alunos das 12 turmas participantes da pesquisa dadas à questão "Conheceu o(s) autor(es) em disciplina, livro ou revista científica?", turmas diurno e noturno da disciplina optativa FLG 437 Teoria Geográfica da Paisagem do Bacharelado em Geografia, ministrada nos segundos semestres de 2006 a 2011 pelo Prof. Dr. Yuri Tavares Rocha, Departamento de Geografia/FFLCH/USP.

\begin{tabular}{cccccccc}
\hline Item citado & $\mathbf{2 0 0 6}$ & $\mathbf{2 0 0 7}$ & $\mathbf{2 0 0 8}$ & $\mathbf{2 0 0 9}$ & $\mathbf{2 0 1 0}$ & $\mathbf{2 0 1 1}$ & Média \\
\hline Disciplina & $54 \%$ & $50 \%$ & $56 \%$ & $64 \%$ & $61 \%$ & $88 \%$ & $\mathbf{6 2 \%}$ \\
\hline Livro & $36 \%$ & $44 \%$ & $34 \%$ & $20 \%$ & $22 \%$ & $6 \%$ & $\mathbf{2 7 \%}$ \\
\hline Revista científica & $0 \%$ & $0 \%$ & $10 \%$ & $16 \%$ & $17 \%$ & $6 \%$ & $\mathbf{8 \%}$ \\
\hline Não citou & $10 \%$ & $6 \%$ & $0 \%$ & $10 \%$ & $0 \%$ & $0 \%$ & $\mathbf{4 \%}$ \\
\hline \multicolumn{7}{c}{ Organização: Yuri Tavares Rocha } &
\end{tabular}

Disciplina foi a fonte mais citada pelos alunos (62\%) de primeiro contato com a paisagem, indicando que a maioria não busca outras fontes além da aula ministrada pelo professor e se restringe aos autores citados por ele. Livro foi a segunda fonte citada (27\%) e revista científica foi a última (8\%), indicando que os alunos praticamente não tem o hábito de consultar, estudar ou buscar informações sobre paisagem em artigos científicos. 


\section{CONSIDERAÇÕES FINAIS}

A comparação entre as estruturas curriculares dos bacharelados em Geografia das universidades estaduais paulistas indicou que apenas a Unicamp não possui uma disciplina obrigatória e ou optativa que apresenta a paisagem em sua denominação, o que indica menor preocupação com uma formação mais ampla do geógrafo. O Bacharelado em Geografia com ênfase em Análise Ambiental e Geoprocessamento, do Instituto de Geociências e Ciências Exatas/campus Rio Claro/Unesp, é o único que possui uma disciplina obrigatória que trata da paisagem como unidade de análise geográfica, significando que seus alunos têm a paisagem valorizada em sua formação.

Nos outros bacharelados da Unesp e no da USP, somente os alunos que optam pela disciplina relacionada à paisagem é que têm sua formação aperfeiçoada com conhecimentos a respeito dessa unidade de análise geográfica. Apesar de o bacharelado da USP possuir uma disciplina optativa sobre paisagem, é o que apresenta menor carga horária (30 horas de aula, dois créditos), metade dos créditos das demais disciplinas dos outros bacharelados.

De forma geral, as estruturas curriculares dos bacharelados em Geografia deveriam considerar as afirmações de Conti $(1998$, p. 148) quanto a não redução da riqueza teóricometodológica da Geografia, construída por seu processo histórico científico, e quanto a não predominância de algumas correntes geográficas que "(...) não só mutilando a verdadeira geografia, que, em nenhum momento de sua evolução, rejeitou o estudo da natureza, como prestaram enorme desserviço, limitando nossa disciplina a um simples proselitismo marxista, de forte conteúdo político e discutível qualidade científica".

Em relação às repostas ao questionário aplicado nas turmas de 2006 a 2011 da disciplina FLG 437 - Teoria Geográfica da Paisagem, pode-se identificar que: o conhecimento prévio predominante sobre paisagem que os alunos têm é pouco elaborado em termos geográficos, frente à riqueza de abordagens existentes; também é influenciado pela adoção preferencial da unidade de análise geográfica espaço em outras disciplinas da estrutura curricular; e, os alunos adquiriram seu conhecimento prévio sobre paisagem nas disciplinas, pouco citando livros e revistas científicas como fontes de consulta, estudo ou busca de informações sobre a paisagem. 
Sugere-se, com base nesta pesquisa e para melhorar a formação dos geógrafos pelo Bacharelado em Geografia da USP, que, numa reforma em sua estrutura curricular, a disciplina optativa FLG 0437 - Teoria Geográfica da Paisagem passe a ser obrigatória e tenha sua carga horária dobrada. Não é recomendável que um curso de Bacharelado em Geografia, ou em qualquer outra área, adote alguma corrente ou unidade de análise geográfica de forma preferencial ou intencional, a não ser que explicite que é um bacharelado com ênfase em alguma especialização.

\section{REFERÊNCIAS BIBLIOGRÁFICAS}

BOLÓS I CAPDEVILA, M. Manual de ciencia del paisaje. Barcelona: Masson, 1992.

BERTRAND, G. La ciencia del paisaje, uma ciencia diagonal (1972). In: MENDOZA, J. G.; JIMÉNEZ, J. M.; CANTERO, N. O. (Org.) El pensamiento geográfico. Madrid: Alianza Editorial, 1982. p. 465-469.

BOBEK, H.; SCHMITHÜSEN, J. El paisaje en el sistemalógico de la geografia, 1949. In: MENDOZA, J. G.; JIMÉNEZ, J. M.; CANTERO, N. O. (Org.) El pensamiento geográfico. Madrid: Alianza Editorial, 1982. p. 330-335.

BRUNET, R. Analisis de paisajes y semiologia (1974). In: MENDOZA, J. G.; JIMÉNEZ, J. M.; CANTERO, N. O. (Org.) El pensamiento geográfico. Madrid: Alianza Editorial, 1982. p. 485493.

BUENO, F. S. Dicionário escolar do professor. Brasília: Ministério da Educação, 1962.

BURLE MARX, R. Arte \& Paisagem. São Paulo: Nobel, 1987.

CAVALHEIRO, F. Intervenção na paisagem: planejamento de espaços livres. In: SANTOS, J. E. et al. (Org.) Faces da polissemia da paisagem: ecologia, planejamento e percepção (1). São Carlos: Rima/Fapesp, 2004. p. 449-455.

CONTI, J. B. Geografia, sazonalidade e paisagem. In: ENCONTRO INTERDISCIPLINAR SOBRE O ESTUDO DA PAISAGEM, 3., 1998, Rio Claro. Anais... Rio Claro: Unesp, 1998, p. 147-153. 
CONTI, J. B. Resgatando a Fisiologia da Paisagem. Revista do Departamento de Geografia/USP, São Paulo, v. 14, p. 59-68, 2001.

FERREIRA, A. B. H.. Novo dicionário Aurélio básico da língua portuguesa. Rio de Janeiro: Editora Nova Fronteira, 1988.

GOMES, E. T. A. Recortes de paisagens na cidade do Recife: uma abordagem geográfica. Recife: Fundação Joaquim Nabuco/Editora Massangana, 2007.

LAURIE, M. Introducción a la arquitectura del paisaje. Barcelona: Gustavo Gili, 1983.

MARANGONI, A. M. M. C. Questionários e entrevistas: algumas considerações. In: VENTURI, L. A. B. (Org.) Praticando geografia: técnicas de campo e laboratório. São Paulo: Oficina de Textos, 2005. p. 167-174.

MATEO-RODRIGUEZ, J. M. Geografía de los paisajes. La Habana: Universidad de la Habana, 2000.

MATEO-RODRÍGUEZ, J. M. Aportes para la formulación de una teoría geográfica de la sostenibilidad ambiental. La Habana: Universidad de la Habana,, 2007.

MEINIG, D. W. The interpretation of ordinary landscape: geographical essays. New York: Oxford University Press, 1979.

MICHAELIS. Moderno Dicionário da Língua Portuguesa. São Paulo: Editora Melhoramentos, 2007.

MONTEIRO, C. A. F. Geossistemas a história de uma procura. São Paulo: Contexto, 2000.

NAVEH, Z.; LIEBERMAN, A. Landscape Ecology: theory and application. New York: SpringerVerlag, 1994.

PRESOTTO, A.; ROCHA, Y. T. Paisagem, teoria e percepção: estudo de caso em Ilhabela (SP). In: SANTOS, J. E. et al. (Org.) Faces da Polissemia da Paisagem: ecologia, planejamento e percepção (3). São Carlos: Rima, 2010. p. 359-377.

SANTOS, M. Metamorfoses do espaço habitado: fundamentos teórico e metodológico da Geografia. São Paulo: Hucitec, 1988. 
SANTOS, M. A natureza do espaço: técnica e tempo, razão e emoção. São Paulo: Edusp, 2006.

SCHAMA, S. Landscape and memory. New York: Vintage Books, 1996.

SOCHAVA, V. B. Por uma teoria de classificação de geossistemas de vida terrestre. São Paulo: Instituto de Geografia/USP, 1978.

TRICART, J. El analisis de sistemas y el estúdio integrado de médio natural (1979). In: MENDOZA, J. G.; JIMÉNEZ, J. M.; CANTERO, N. O. (Org.) El pensamiento geográfico. Madrid: Alianza Editorial, 1982. p. 470-476.

TROLL, C. El paisaje geográfico y su investigación (1950). In: MENDOZA, J. G.; JIMÉNEZ, J. M.; CANTERO, N. O. (Org.) El pensamiento geográfico. Madrid: Alianza Editorial, 1982. p. 323329.

TUAN, Y. F. Topofilia: um estudo da percepção, atitudes e valores do meio ambiente. São Paulo: Difel, 1980.

\section{AGRADECIMENTOS}

A todos os alunos das turmas diurno e noturno da disciplina optativa FLG 437 - Teoria Geográfica da Paisagem, ministradas no segundo semestre de 2006 a 2011 pelo Prof. Dr. Yuri Tavares Rocha no Bacharelado em Geografia do Departamento de Geografia/FFLCH/USP, que participaram, voluntariamente, da pesquisa e possibilitaram a redação deste artigo. 